\title{
Use of neuron-specific enolase for assessing the severity and outcome in patients with neurological disorders
}

\section{J.E. Lima1, \\ O.M. Takayanagui ${ }^{1}$, \\ L.V. Garcia ${ }^{2}$ and \\ J.P. Leite ${ }^{1}$}

\author{
Departamentos de ${ }^{1}$ Neurologia and ${ }^{2}$ Anestesiologia, \\ Faculdade de Medicina de Ribeirão Preto, \\ Universidade de São Paulo, Ribeirão Preto, SP, Brasil
}

\author{
Correspondence \\ J.P. Leite \\ Departamento de Neurologia \\ FMRP, USP \\ Av. Bandeirantes, 3900 \\ 14048-900 Ribeirão Preto, SP \\ Brasil \\ Fax: +55-16-633-0760 \\ E-mail: jpleite@fmrp.usp.br \\ Research supported by $\mathrm{CNPq}$ and \\ FAPESP (No. 03/00188-8).
}

Received September 4, 2003 Accepted October 8, 2003

\begin{abstract}
Neuron-specific enolase (NSE) is a glycolytic enzyme present almost exclusively in neurons and neuroendocrine cells. NSE levels in cerebrospinal fluid (CSF) are assumed to be useful to estimate neuronal injury and clinical outcome of patients with serious clinical manifestations such as those observed in stroke, head injury, anoxic encephalopathy, encephalitis, brain metastasis, and status epilepticus. We compared levels of NSE in serum (sNSE) and in CSF (cNSE) among four groups: patients with meningitis $(\mathrm{N}=11)$, patients with encephalic injuries associated with impairment of consciousness (ENC, $\mathrm{N}=$ 7 ), patients with neurocysticercosis $(\mathrm{N}=25)$, and normal subjects $(\mathrm{N}=8)$. Albumin was determined in serum and CSF samples, and the albumin quotient was used to estimate blood-brain barrier permeability. The Glasgow Coma Scale score was calculated at the time of lumbar puncture and the Glasgow Outcome Scale (GOS) score was calculated at the time of patient discharge or death. The ENC group had significantly higher $\mathrm{cNSE}(\mathrm{P}=0.01)$ and albumin quotient $(\mathrm{P}=$ $0.005)$, but not sNSE $(P=0.14)$, levels than the other groups (KruskalWallis test). Patients with lower GOS scores had higher cNSE levels $(\mathrm{P}=0.035)$ than patients with favorable outcomes. Our findings indicate that SNSE is not sensitive enough to detect neuronal damage, but cNSE seems to be reliable for assessing patients with considerable neurological insult and cases with adverse outcome. However, one should be cautious about estimating the severity of neurological status as well as outcome based exclusively on cNSE in a single patient.
\end{abstract}

\section{Introduction}

Enolase (2-phospho-D glycerate hydrolyase or phosphopyruvate hydratase, EC 4.2.1.11) is a glycolytic enzyme that converts 2-phospho-D glycerate to phosphoenolpyruvate. It is a protein which is functionally active as a heterodimer assembled
Key words

- Neuronal damage

- Neuron-specific enolase

- Cerebrospinal fluid

- Albumin quotient from a combination of three subunits: $\alpha, \beta$ and $\gamma$ (1). The $\gamma \gamma$ and $\alpha \gamma$ isoenzymes are referred to as neuron-specific enolase (NSE) $(2,3)$ because it was initially thought that these isoenzymes were exclusively found in neurons (4). However, it was subsequently shown that neuroendocrine cells and several non-neuronal and non-neuroendocrine cells 
also contained NSE. In contrast to neurons which express the $\gamma \gamma$ isoenzyme, non-neuronal cells contain predominantly the $\alpha \gamma$ isoenzyme (3).

The encephalic NSE concentration ranges from 0.4 to $2.2 \%$, and may represent up to $4 \%$ of the total soluble proteins in some neurons (3). In adult brains, higher concentrations of NSE are found in the gray matter (e.g., neocortex) and lower levels in the white matter (e.g., pyramidal tract and corpus callosum) (2).

NSE was also reported to be present in platelets and red blood cells $(5,6)$. The presence of NSE in red blood cells is clinically relevant because even a mild hemolysis of $2 \%$ may increase serum NSE (sNSE) levels five-fold (7).

Besides being expressed selectively in neurons, NSE has a high stability in biological fluids and, as a free soluble cytoplasmic protein, can easily diffuse to the extracellular medium and cerebrospinal fluid (CSF) when neuronal membranes are injured. Hence, measurements of CSF-NSE (cNSE) may be an attractive marker of neuronal damage $(2,3)$. There are some peculiarities, however, that have to be considered when cNSE or other CSF neuronal markers are assayed: nature, location and extension of the lesion; CSF turnover and time elapsed between neuronal injury and CSF sample collection $(8,9)$.

Several studies have shown that cNSE yields a reliable estimate of the severity of neuronal injury as well as clinical outcome of patients with serious clinical manifestations such as in cases of stroke (10), head injury (11), anoxic encephalopathy (12), encephalitis (13), brain metastasis (8), and status epilepticus (14).

The results, however, are inconsistent in less severe or chronic neurological disorders (15). It has been suggested that there may be an increase of cNSE at earlier stages of neurodegenerative disorders, followed by a gradual decrease as the disease progresses.
In such advanced stages, most neurons are already degenerate. Indeed, reduced cNSE levels have been described in Alzheimer's disease (16). In contrast to other demential disorders, high cNSE levels have been described in Creutzfeldt-Jacob disease $(17,18)$. It has been suggested that CNSE and CSF 143-3 protein may represent relevant information to establish the diagnosis of CreutzfeldtJacob disease. Patients with a clinical picture indicative of "possible" disease could be considered "probable" cases of Creutzfeldt-Jacob disease if there is an association of high CSF levels of NSE and 14-3-3 protein (19). In the variant form of CreutzfeldtJacob disease, it has been shown that cNSE is less sensitive as an indicator, probably because of the slower progression of the variant form (20).

Due to the obvious ethical obstacles for performing CSF collection in some neurological disorders, several studies have suggested the use of sNSE to estimate neuronal damage or neurological outcome. However, the integrity of the blood-brain barrier is not always altered in such disorders and NSE may not reach the serum compartment. Hence, the interpretation of studies using only sNSE has been controversial. Some have provided positive results (21-25) while others have not (26-31). Another restriction of the interpretation of sNSE levels is the putative presence of hemolysis that could lead to false-positive results.

The aim of the present study was to determine if NSE levels would be expressed differentially according to the severity of neurological impairment. Hence, we expect that neurological disorders associated with poorer Glasgow Coma Scale and Glasgow Outcome Scale scores would present higher NSE levels.

\section{Subjects and Methods}

\section{Subjects}

All patients included in this study were 
chosen prospectively among patients who underwent lumbar puncture due to medical indication. The study was approved by the Ethics Committee of our institution and informed consent was obtained from all subjects.

The Glasgow Coma Scale score (32) was calculated at the time of lumbar puncture and the Glasgow Outcome Scale score (33) was obtained at the time of patient discharge or death. The Glasgow Outcome Scale was used with some modifications as follows: score 1 - death; score 2 - persistent vegetative state; score 3 - severe disability, patients who are unable to perform activities of daily living, dependent on others for self-care; score 4 - mild disability, patients able to perform activities of daily living but with a motor or cognitive deficit; score 5 - normal neurological status.

Patients were divided into four groups according to etiology and/or neurological status: 1) patients with meningitis who presented a score of 15 on the Glasgow Coma Scale; 2) patients with encephalic injuries who presented a score of 14 or less on the Glasgow Coma Scale (ENC); 3) patients with a diagnosis of neurocysticercosis based on clinical, neuroimaging, immunodiagnostic reactions and epidemiological data (34); 4) a control group.

The control group included patients without any neurological or systemic disorders who underwent lumbar puncture for spinal anesthesia for inguinal herniotomy or orthopedic surgeries, or patients with chronic headache who had normal clinical examination, neuroimaging, CSF and other ancillary exams, and who were diagnosed as having tension headache.

\section{CSF and serum samples}

CSF and peripheral blood samples were collected simultaneously and centrifuged for $10 \mathrm{~min}$ at $2500 \mathrm{~g} ; 1 \mathrm{ml}$ of the cell-free samples was immediately frozen and stored at $-70^{\circ} \mathrm{C}$ until analysis. Hemolyzed serum samples and CSF samples containing erythrocytes were excluded. Control CSF samples were obtained at the time of lumbar puncture performed for spinal anesthesia, before the anesthetic was injected. All samples were thawed and analyzed in a single series. NSE was assayed by a commercial enzyme immunoassay kit (Cobas Core NSE EIA II; Roche, Basel, Switzerland) (35).

Quantitative determination of albumin by nephelometry (BN-100; Dade Behring, Marburg, Germany) was also performed in serum and CSF samples, and the CSF/serum albumin concentration ratio (albumin quotient, Qalb) was used as a measure of bloodbrain barrier permeability (36).

\section{Statistical analysis}

The Kruskal-Wallis test, followed by the post hoc Dunn test, was used to compare age, cNSE, sNSE and Qalb among groups and between groups and controls. The MannWhitney U-test was used to compare cNSE and SNSE between patients with Glasgow Outcome Scale scores $1+3$ and patients with Glasgow Outcome Scale scores $4+5$. Nonparametric linear regression analysis based on Kendall's rank correlation test was used to correlate NSE with age and several CSF and serum parameters. A P value of $<0.05$ was used for significance.

\section{Results}

Fifty-one subjects, 28 men and 23 women ranging in age from 13 to 82 years (mean = 38 , median $=37$ ) were enrolled in the study. There was no difference in age among groups $(\mathrm{P}=0.65)$. There was no difference in NSE levels between males (cNSE: mean $\pm \mathrm{SD}=$ $9.7 \pm 23.0 \mathrm{ng} / \mathrm{ml}$, median $=3.6 \mathrm{ng} / \mathrm{ml} ;$ sNSE: $8.8 \pm 10.3,6.7 \mathrm{ng} / \mathrm{ml}$ ) and females (cNSE: $7.8 \pm 7.9,6.1 \mathrm{ng} / \mathrm{ml}$; sNSE: $7.3 \pm 7.3,5.8 \mathrm{ng} /$ $\mathrm{ml}$; cNSE: $\mathrm{P}=0.10$; sNSE: $\mathrm{P}=0.81)$. Nonparametric linear regression analysis did not show any correlation between the following 
Table 1. Distribution of neuron-specific enolase (NSE) levels and albumin quotient among the groups studied.

\begin{tabular}{|c|c|c|c|c|c|c|c|}
\hline \multirow[t]{2}{*}{ Group } & \multirow[t]{2}{*}{$\mathrm{N}$} & \multicolumn{2}{|c|}{ cNSE (ng/ml) } & \multicolumn{2}{|c|}{ sNSE (ng/ml) } & \multicolumn{2}{|c|}{ Qalb $\left(\times 10^{-3}\right)$} \\
\hline & & Mean \pm SD & Median & Mean \pm SD & Median & Mean \pm SD & Median \\
\hline MEN & 11 & $4.9 \pm 4.6$ & 4.4 & $5.8 \pm 4.6$ & 5.4 & $6.9 \pm 3.3$ & 5.9 \\
\hline ENC & 7 & $35.8 \pm 39.2^{*}$ & 29.7 & $20.9 \pm 19.2$ & 9.2 & $33.8 \pm 60.3^{*}$ & 9.5 \\
\hline NC & 25 & $3.9 \pm 3.2$ & 3.0 & $6.6 \pm 3.4$ & 7.1 & $4.1 \pm 2.5$ & 3.4 \\
\hline CON & 8 & $6.3 \pm 3.6$ & 6.1 & $4.7 \pm 2.3$ & 4.9 & $3.4 \pm 1.4$ & 3.2 \\
\hline
\end{tabular}

$\mathrm{CON}=$ control; $\mathrm{cNSE}=$ NSE in cerebrospinal fluid; $\mathrm{ENC}=$ encephalic; $\mathrm{MEN}=$ meningitis; NC = neurocysticercosis; sNSE = serum NSE. The albumin quotient (Qalb) is the ratio CSF albumin concentration/serum albumin concentration. The ENC group had higher levels of cNSE ( $\left.{ }^{*} P=0.01\right)$ and Qalb ( $\left.{ }^{*} P=0.0047\right)$, but not of sNSE ( $P=$ 0.14 ), compared to the other groups (Kruskal-Wallis test followed by the Dunn test).

Table 2. Distribution of neuron-specific enolase (NSE) levels, albumin quotient (Qalb) and clinical data among patients with encephalic disorders (ENC).

\begin{tabular}{lccrrrrrr} 
Patient & Diagnosis & $\begin{array}{c}\text { Duration of } \\
\text { symptoms }\end{array}$ & $\begin{array}{c}\text { cNSE } \\
(\mathrm{ng} / \mathrm{ml})\end{array}$ & $\begin{array}{c}\text { sNSE } \\
(\mathrm{ng} / \mathrm{ml})\end{array}$ & $\begin{array}{r}\text { Qalb } \\
\left(\times 10^{-3}\right)\end{array}$ & $\begin{array}{r}\text { GCS } \\
\text { score }\end{array}$ & $\begin{array}{c}\text { GOS } \\
\text { score }\end{array}$ & Cells $/ \mathrm{mm}^{3}$ \\
\hline ENC1 & NCSE & 7 days & 12.5 & 9.2 & 26.31 & 10 & 1 & 1.3 \\
ENC2 & ADEM & 8 days & 4.9 & 6.4 & 4.41 & 9 & 3 & 0.6 \\
ENC3 & PM & $5 \mathrm{~h}$ & 3.8 & 2.2 & 169.46 & 13 & 1 & 6.3 \\
ENC4 & HE & 5 days & 52.9 & 36.6 & 7.80 & 11 & 3 & 36.6 \\
ENC5 & LC & 21 days & 31.1 & 37.6 & 3.57 & 7 & 3 & 0.0 \\
ENC6 & NT & 20 days & 115.5 & 48.4 & 15.23 & 12 & 1 & 4.6 \\
ENC7 & CV & 2 days & 29.7 & 5.9 & 9.51 & 14 & 5 & 97.0 \\
Mean & & & 35.8 & 20.9 & 33.76 & & & 20.9 \\
SD & & & 39.2 & 19.2 & 60.34 & & & 35.9 \\
Median & & & 29.7 & 9.2 & 9.51 & & & 4.6
\end{tabular}

ADEM = acute disseminated encephalomyelitis; CNSE = NSE in cerebrospinal fluid; $\mathrm{CV}=$ cerebral vasculitis; duration of symptoms = period of time between the onset of symptoms and enrollment in the study; GCS = Glasgow Coma Scale; GOS = Glasgow Outcome Scale; $\mathrm{HE}=$ herpetic encephalitis; $\mathrm{LC}=$ lupus cerebritis; NCSE = nonconvulsive status epilepticus; NT = neurotoxoplasmosis; PM = pneumococcal meningitis; SNSE $=$ serum NSE. Cells $=$ number of CSF cells $/ \mathrm{mm}^{3}$.

Table 3. Distribution of neuron-specific enolase (NSE) levels according to Glasgow Outcome Scale (GOS) scores.

\begin{tabular}{lrrrrrr}
\hline \multirow{2}{*}{$\begin{array}{l}\text { GOS } \\
\text { scores }\end{array}$} & \multirow{2}{*}{ N } & \multicolumn{2}{c}{ cNSE (ng/ml) } & & \multicolumn{2}{c}{ SNSE (ng/ml) } \\
\cline { 3 - 4 } & & Mean \pm SD & Median & & Mean \pm SD & Median \\
\hline $1+3$ & 7 & $31.56 \pm 41.49$ & $12.50^{*}$ & & $20.71 \pm 19.34$ & 9.20 \\
$4+5$ & 44 & $5.25 \pm 5.25$ & 4.40 & & $6.09 \pm 3.54$ & 5.85 \\
\hline
\end{tabular}

cNSE = NSE in cerebrospinal fluid; sNSE = serum NSE.

${ }^{*} \mathrm{P}=0.035$ compared to GOS $4+5$ (Mann-Whitney test). variables: age and cNSE, age and Qalb, CSF protein levels and cNSE, CSF number of cells and cNSE, cNSE and Qalb, or sNSE and Qalb $(\mathrm{P}=0.23)$.

Levels of cNSE and sNSE in subjects with CSF pleocytosis (cell counts $>5 / \mathrm{mm}^{3}$ ) $(\mathrm{N}=24$; cNSE: mean $\pm \mathrm{SD}=7.3 \pm 11.6 \mathrm{ng} /$ $\mathrm{ml}$, median $=3.7 \mathrm{ng} / \mathrm{ml}$; sNSE: $7.8 \pm 7.4,6.5$ $\mathrm{ng} / \mathrm{ml}$; Qalb: $13.2 \pm 34.2 \times 10^{-3}, 5.8 \times 10^{-3}$ ) were not different from those of subjects with normal CSF cell counts $(\mathrm{N}=27$; cNSE: $10.3 \pm 21.9,6.1 \mathrm{ng} / \mathrm{ml}$; sNSE: $8.3 \pm 10.4,6.4$ $\mathrm{ng} / \mathrm{ml}$; Qalb: $5.4 \pm 5.5 \times 10^{-3}, 3.5 \times 10^{-3}$ ); however, Qalb was higher in those with pleocytosis (cNSE: $\mathrm{P}=0.30$; sNSE: $\mathrm{P}=$ 0.61; Qalb: $\mathrm{P}=0.033$ ). Levels of cNSE and sNSE in subjects with CSF protein levels $>45 \mathrm{mg} \%(\mathrm{~N}=13$; cNSE: $18.4 \pm 32.8,5.6$ ng/ml; sNSE: $11.2 \pm 14.5,7.9 \mathrm{ng} / \mathrm{ml}$; Qalb: $23.3 \pm 46.3 \times 10^{-3}, 8.7 \times 10^{-3}$ ) did not differ from those with CSF proteins $\geq 45 \mathrm{mg} \%$ ( $\mathrm{N}=$ 38; cNSE: $5.6 \pm 5.6,4.7 \mathrm{ng} / \mathrm{ml}$; sNSE: $7.0 \pm$ 6.1, $6.1 \mathrm{ng} / \mathrm{ml}$; Qalb: $4.5 \pm 3.2 \times 10^{-3}, 3.5 \mathrm{x}$ $10^{-3}$ ) but Qalb was higher (cNSE: $\mathrm{P}=0.59$; sNSE: $\mathrm{P}=0.66$; Qalb: $\mathrm{P}<0.0001$ ).

The number of subjects and the main laboratory results of the four groups are presented in Table 1. The comparison of cNSE levels among groups is represented in Figure 1. Table 2 describes the clinical and laboratory data of each patient from the ENC group. In the ENC group, nonparametric linear regression analysis did not show a correlation between Qalb and cNSE or between Qalb and SNSE.

Considering all subjects, cNSE levels did not correlate with sNSE (Figure 2). However, when only patients of the ENC group were considered there was a positive correlation between cNSE and SNSE (Figure 3).

Table 3 presents the cNSE and sNSE values according to clinical outcome. Patients with Glasgow Outcome Scale scores $1+3$ had significantly higher cNSE levels than patients with Glasgow Outcome Scale scores $4+5(P=0.035$; Figure 4). Patients with Glasgow Outcome Scale scores $1+3$ 
also had significantly higher levels of Qalb $(P=0.0499)$. Serum NSE levels showed a trend to be significant between the two groups $(\mathrm{P}=0.0515)$.

\section{Discussion}

The present findings indicate that patients in the ENC group had higher cNSE levels than patients from the other groups. The ENC group was characterized by heterogeneous neurological disorders that had in common lower scores on the Glasgow Coma Scale. These results indicate that cNSE provides a good indicator of brain injury, as suggested by previous studies $(10-12,14)$.

Due to ethical restrictions and limitations of lumbar puncture, estimation of SNSE would be a more convenient approach, allowing serial sample collections. Literature data have shown discrepancies among studies concerning the exclusive use of sNSE to estimate neuronal damage $(26,28-30)$. One could expect that cNSE could be replaced by SNSE at least in cases which present bloodbrain barrier disruption. Our findings indicated, however, that even in the ENC group, which had evidence of blood-brain barrier disruption (indicated by elevated Qalb), sNSE levels were not significantly higher than in the other groups, suggesting that SNSE is not a realiable indicator of neuronal damage.

The lack of an increase of sNSE and/or cNSE in patients with meningitis, who had normal Glasgow Coma Scale scores, was not particularly surprising, since in this situation the inflammatory involvement of brain parenchyma is probably negligible (37). This also seems to be true in conditions associated with involvement of a small proportion of brain parenchyma. We have recently shown that patients with neurocysticercosis with less than five degenerating cysts also had normal cNSE and sNSE levels, indicating that the inflammatory response associated with a relatively small number of degenerating cysts does not provoke sufficient neuronal damage to increase NSE levels (38).

A detailed observation of patients from the ENC group discloses some pitfalls of the use of cNSE as a tool to estimate the severity of brain injury. In patient ENC2, who had acute disseminated encephalomyelitis, cNSE was within the normal range 8 days after the onset of symptoms, despite the fact that the patient presented a score of 9 on the Glasgow Coma Scale. The normal levels of cNSE may

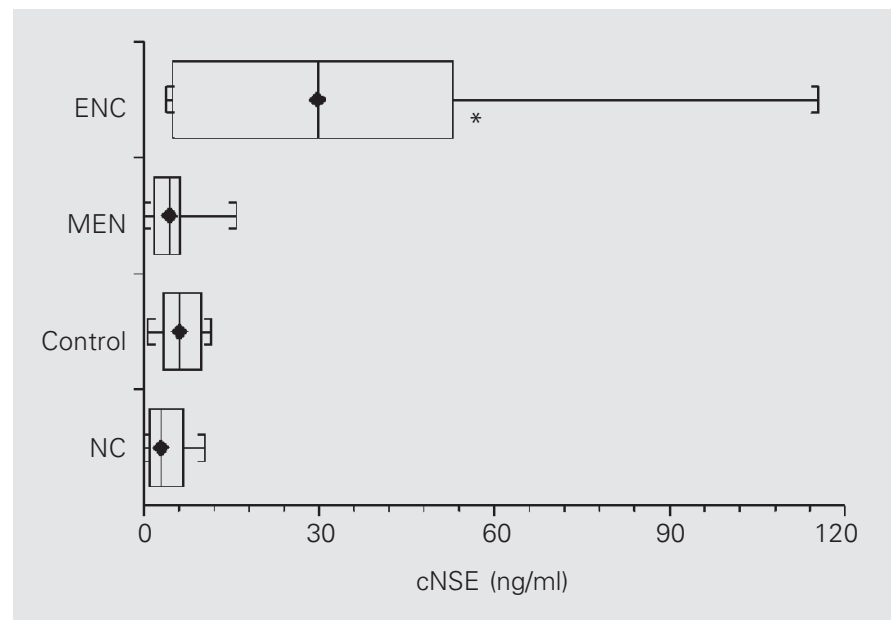

Figure 1. Distribution of neuron-specific enolase levels in cerebrospinal fluid (cNSE) in patients with encephalic disease (ENC; $N=7$ ), meningitis (MEN; $N=11)$ and neurocysticercosis ( $N C ; N=25)$. Control $(N=8) .{ }^{*} P=0.01$ compared to the other groups (Kruskal-Wallis test).

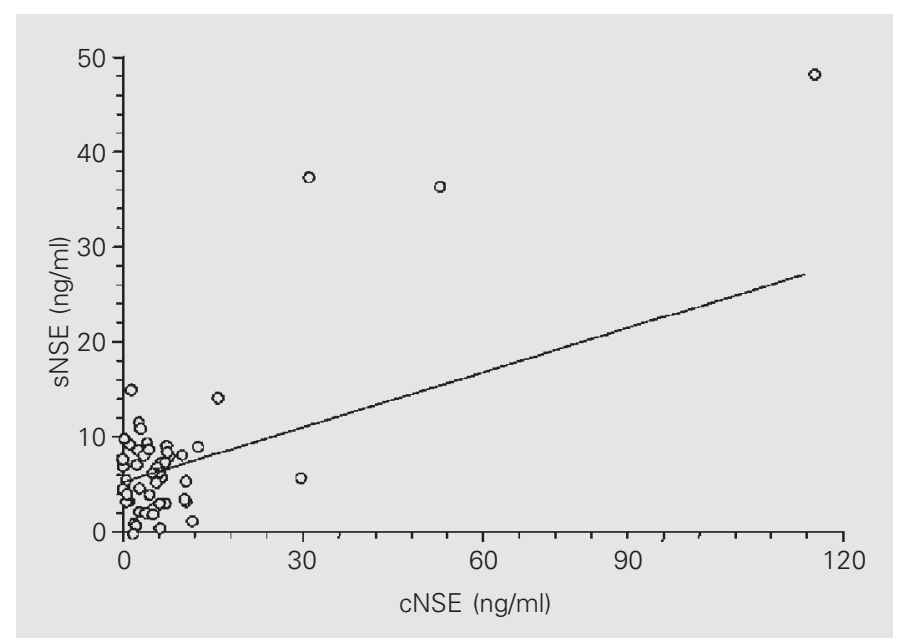

Figure 2. Nonparametric linear regression analysis of neuron-specific enolase levels in serum (sNSE) and neuron-specific enolase levels in cerebrospinal fluid (cNSE) for all subjects ( $N=51$ ). $P=0.16$ (Kendall's rank correlation coefficient tau $b=0.135808$ ). 
be due to the fact that acute disseminated encephalomyelitis predominantly affects white matter (39), which contains lower concentrations of NSE. An alternative explanation is that NSE had been elevated at the onset of symptoms but had returned to normal levels at the time of lumbar puncture.

One unexpected finding in our series concerned patient ENC3, who had pneumococcal meningoencephalitis and died of sepsis 3

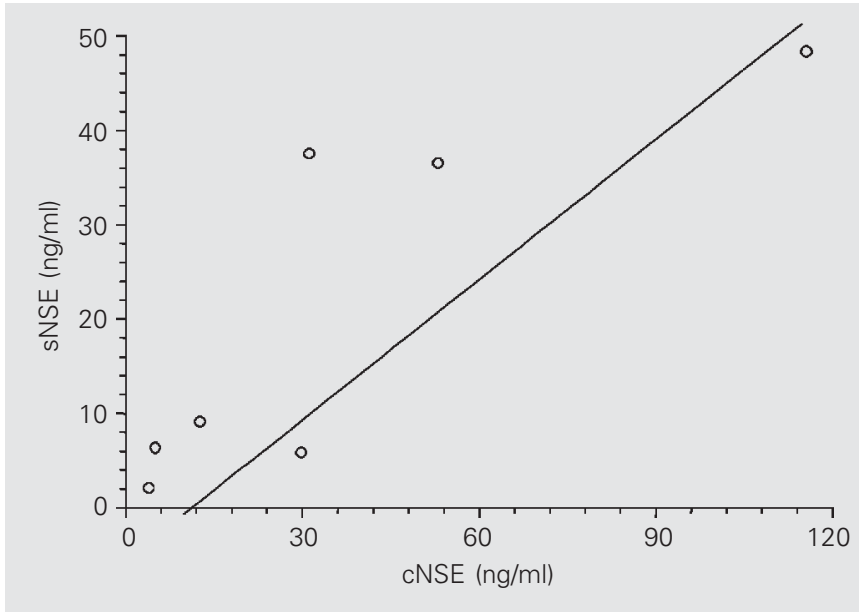

Figure 3. Nonparametric linear regression analysis of neuron-specific enolase levels in serum (SNSE) and neuron-specific enolase levels in cerebrospinal fluid (cNSE) of the encephalic $(E N C)$ group $(N=7) . P=0.035$ (Kendall's rank correlation coefficient tau $\mathrm{b}=0.714286$ ).

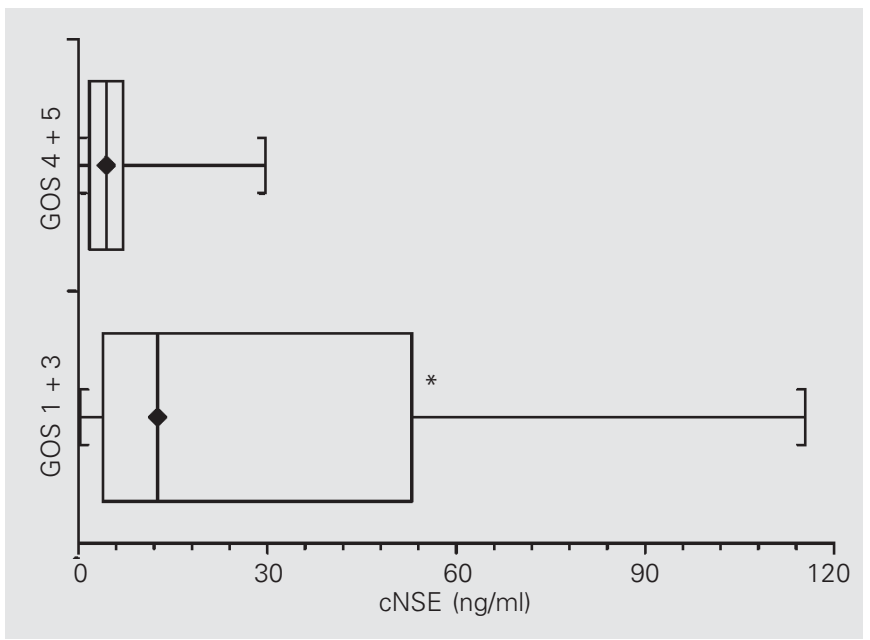

Figure 4. Distribution of neuron-specific enolase levels in cerebrospinal fluid (CNSE) of subjects with scores $1+3(N=7)$ on the Glasgow Outcome Scale (GOS) and of subjects with scores $4+5$ on the GOS. ${ }^{*} \mathrm{P}=$ 0.035 compared to GOS $4+5(N=44)$ (Mann-Whitney test). days later. NSE levels were within the normal range $5 \mathrm{~h}$ after the onset of symptoms, when the patient had a Glasgow Coma Scale score of 13. Although cases of meningitis are not usually associated with increased NSE levels, we would expect some elevation when there is an indication of encephalic involvement. In addition, cNSE was unable to predict the death outcome. We might speculate that that at the time of lumbar puncture the patient was already in a septic state. The lower Glasgow Coma Scale score could be caused by a diffuse encephalopathy without direct involvement of brain parenchyma. However, a previous study has suggested that sNSE might be used to predict the death outcome in patients with sepsis (40).

The present study indicated that there was a significant difference in cNSE levels between groups of patients with Glasgow Outcome Scale scores $1+3$ and with Glasgow Outcome Scale scores $4+5$. Although the present study had a relatively small number of patients, we suggest that cNSE might be a useful parameter to estimate the unfavorable outcome in this set of patients. However, the pitfall cases presented earlier illustrate the limitations of NSE levels as an isolated prognostic parameter.

Of the seven patients in the ENC group, four (ENC1, ENC4, ENC5 and ENC6) presented an agreement between elevated NSE levels and poor prognosis, two (ENC2 and ENC3) had normal NSE levels but presented unfavorable outcomes (Glasgow Outcome Scale score 1 or 3), and one patient (ENC7) had elevated NSE levels, but his outcome was favorable (Glasgow Outcome Scale score 5).

Our findings indicate that sNSE is not sensitive enough to detect neuronal damage, but cNSE seems to be a reliable parameter for assessing patients with considerable neurological insult as well as cases with adverse outcome. However, the estimate in a single patient of the severity of neurological status as well as outcome based exclusively on cNSE should be considered with caution. 


\section{References}

1. Fletcher L, Rider CC \& Taylor CB (1976). Enolase isoenzymes. III. Chromatographic and immunological characteristics of rat brain enolase. Biochimica et Biophysica Acta, 452: 245-252.

2. Marangos PJ, Schmechel D, Parma AM, Clark RL \& Goodwin FK (1979). Measurement of neuron-specific (NSE) and non-neuronal (NNE) isoenzymes of enolase in rat, monkey and human nervous tissue. Journal of Neurochemistry, 33: 319-329.

3. Marangos PJ \& Schmechel DE (1987). Neuron specific enolase, a clinically useful marker for neurons and neuroendocrine cells. Annual Review of Neuroscience, 10: 269-295.

4. Rider CC \& Taylor CB (1975). Evidence for a new form of enolase in rat brain. Biochemical and Biophysical Research Communications, 66: 814-820.

5. Marangos PJ, Campbell IC, Schmechel DE, Murphy DL \& Goodwin FK (1980). Blood platelets contain a neuron-specific enolase subunit. Journal of Neurochemistry, 34: 1254-1258.

6. Day IN \& Thompson RJ (1984). Levels of immunoreactive aldolase $\mathrm{C}$, creatine kinase-BB, neuronal and non-neuronal enolase, and 143-3 protein in circulating human blood cells. Clinica Chimica Acta, 136: $219-228$

7. Anastasiades KD, Mullins RE \& Conn RB (1987). Neuron-specific enolase. Assessment by ELISA in patients with small cell carcinoma of the lung. American Journal of Clinical Pathology, 87: 245-249.

8. Royds JA, Timperley WR \& Taylor CB (1981). Levels of enolase and other enzymes in the cerebrospinal fluid as indices of pathological change. Journal of Neurology, Neurosurgery and Psychiatry, 44: 1129-1135.

9. Hardemark HG, Ericsson N, Kotwica Z, Rundstrom G, MendelHartvig I, Olsson Y, Pahlman S \& Persson L (1989). S-100 protein and neuron-specific enolase in CSF after experimental traumatic or focal ischemic brain damage. Journal of Neurosurgery, 71: 727-731.

10. Hay E, Royds JA, Davies-Jones GA, Lewtas NA, Timperley WR \& Taylor CB (1984). Cerebrospinal fluid enolase in stroke. Journal of Neurology, Neurosurgery and Psychiatry, 47: 724-729.

11. Persson L, Hardemark HG, Gustafsson J, Rundstrom G, MendelHartvig I, Esscher T \& Pahlman S (1987). S-100 protein and neuronspecific enolase in cerebrospinal fluid and serum: markers of cell damage in human central nervous system. Stroke, 18: 911-918.

12. Roine RO, Somer H, Kaste M, Viinikka L \& Karonen SL (1989). Neurological outcome after out-of-hospital cardiac arrest. Prediction by cerebrospinal fluid enzyme analysis. Archives of Neurology, 46: 753-756

13. Studahl M, Rosengren L, Gunther G \& Hagberg L (2000). Difference in pathogenesis between herpes simplex virus type 1 encephalitis and tick-borne encephalitis demonstrated by means of cerebrospinal fluid markers of glial and neuronal destruction. Journal of Neurology, 247: 636-642.

14. Correale J, Rabinowicz AL, Heck CN, Smith TD, Loskota WJ \& DeGiorgio CM (1998). Status epilepticus increases CSF levels of neuron-specific enolase and alters the blood-brain barrier. Neurology, 50: 1388-1391.

15. Jacobi C \& Reiber H (1988). Clinical relevance of increased neuronspecific enolase concentration in cerebrospinal fluid. Clinica Chimica Acta, 177: 49-54.

16. Cutler NR, Kay AD, Marangos PJ \& Burg C (1986). Cerebrospinal fluid neuron-specific enolase is reduced in Alzheimer's disease. Archives of Neurology, 43: 153-154.

17. Zerr I, Bodemer M, Racker S, Grosche S, Poser S, Kretzschmar HA
\& Weber $T$ (1995). Cerebrospinal fluid concentration of neuronspecific enolase in diagnosis of Creutzfeldt-Jakob disease. Lancet, 345: 1609-1610.

18. Kropp S, Zerr I, Schulz-Schaeffer WJ, Riedemann C, Bodemer M, Laske C, Kretzschmar HA \& Poser S (1999). Increase of neuronspecific enolase in patients with Creutzfeldt-Jakob disease. Neuroscience Letters, 261: 124-126.

19. Aksamit Jr AJ, Preissner CM \& Homburger HA (2001). Quantitation of 14-3-3 and neuron-specific enolase proteins in CSF in CreutzfeldtJakob disease. Neurology, 57: 728-730.

20. Green AJ, Thompson EJ, Stewart GE, Zeidler M, McKenzie JM, MacLeod MA, Ironside JW, Will RG \& Knight RS (2001). Use of 143-3 and other brain-specific proteins in CSF in the diagnosis of variant Creutzfeldt-Jakob disease. Journal of Neurology, Neurosurgery and Psychiatry, 70: 744-748.

21. Schaarschmidt H, Prange HW \& Reiber H (1994). Neuron-specific enolase concentrations in blood as a prognostic parameter in cerebrovascular diseases. Stroke, 25: 558-565.

22. Fogel W, Krieger D, Veith M, Adams HP, Hund E, StorchHagenlocher B, Buggle F, Mathias D \& Hacke W (1997). Serum neuron-specific enolase as early predictor of outcome after cardiac arrest. Critical Care Medicine, 25: 1133-1138.

23. Schoerkhuber W, Kittler H, Sterz F, Behringer W, Holzer M, Frossard M, Spitzauer S \& Laggner AN (1999). Time course of serum neuronspecific enolase. A predictor of neurological outcome in patients resuscitated from cardiac arrest. Stroke, 30: 1598-1603.

24. Buttner T, Lack B, Jager M, Wunsche W, Kuhn W, Muller T, Przuntek H \& Postert T (1999). Serum levels of neuron-specific enolase and s100 protein after single tonic-clonic seizures. Journal of Neurology, 246: 459-461.

25. DeGiorgio $\mathrm{CM}$, Heck CN, Rabinowicz AL, Gott PS, Smith $T$ \& Correale J (1999). Serum neuron-specific enolase in the major subtypes of status epilepticus. Neurology, 52: 746-749.

26. Karkela J, Bock E \& Kaukinen S (1993). CSF and serum brainspecific creatine kinase isoenzyme (CK-BB), neuron-specific enolase (NSE) and neural cell adhesion molecule (NCAM) as prognostic markers for hypoxic brain injury after cardiac arrest in man. Journal of the Neurological Sciences, 116: 100-109.

27. Usui A, Kato K, Murase M, Hotta T, Tanaka M, Takeuchi E \& Abe T (1994). Neural tissue-related proteins (NSE, GO alpha, 28-kDa calbindin-D, S100b and CK-BB) in serum and cerebrospinal fluid after cardiac arrest. Journal of the Neurological Sciences, 123: 134-139.

28. Johnsson P, Blomquist S, Luhrs C, Malmkvist G, Alling C, Solem JO \& Stahl E (2000). Neuron-specific enolase increases in plasma during and immediately after extracorporeal circulation. Annals of Thoracic Surgery, 69: 750-754

29. Missler U, Wiesmann M, Friedrich C \& Kaps M (1997). S-100 protein and neuron-specific enolase concentrations in blood as indicators of infarction volume and prognosis in acute ischemic stroke. Stroke, 28: 1956-1960

30. Fassbender K, Schmidt R, Schreiner A, Fatar M, Muhlhauser F, Daffertshofer M \& Hennerici M (1997). Leakage of brain-originated proteins in peripheral blood: temporal profile and diagnostic value in early ischemic stroke. Journal of the Neurological Sciences, 148: 101-105.

31. Tumani H, Otto M, Gefeller O, Wiltfang J, Herrendorf G, Mogge S \& Steinhoff BJ (1999). Kinetics of serum neuron-specific enolase and prolactin in patients after single epileptic seizures. Epilepsia, 40: 
713-718.

32. Teasdale G \& Jennett B (1974). Assessment of coma and impaired consciousness. A practical scale. Lancet, 2: 81-84.

33. Jennett B \& Bond M (1975). Assessment of outcome after severe brain damage. Lancet, 1: 480-484.

34. Del Brutto OH, Rajshekhar V, White Jr AC et al. (2001). Proposed diagnostic criteria for neurocysticercosis. Neurology, 57: 177-183.

35. Sterk M, Oenings A, Eymann E \& Roos W (1999). Development of a new automated enzyme immunoassay for the determination of neuron-specific enolase. Anticancer Research, 19: 2759-2762.

36. Tibbling G, Link H \& Ohman S (1977). Principles of albumin and IgG analyses in neurological disorders. I. Establishment of reference values. Scandinavian Journal of Clinical and Laboratory Investigation, 37: 385-390.

37. Mokuno K, Kato K, Kawai K, Matsuoka Y, Yanagi T \& Sobue I (1983).
Neuron-specific enolase and S-100 protein levels in cerebrospinal fluid of patients with various neurological diseases. Journal of the Neurological Sciences, 60: 443-451.

38. Lima JE, Takayanagui OM, Garcia LV \& Leite JP (2004). Neuronspecific enolase in patients with neurocysticercosis. Journal of the Neurological Sciences, 217: 31-35.

39. Dale RC, de Sousa C, Chong WK, Cox TC, Harding B \& Neville BG (2000). Acute disseminated encephalomyelitis, multiphasic disseminated encephalomyelitis and multiple sclerosis in children. Brain, 123: 2407-2422.

40. Weigand MA, Volkmann $M$, Schmidt $H$, Martin $E$, Bohrer $H$ \& Bardenheuer HJ (2000). Neuron-specific enolase as a marker of fatal outcome in patients with severe sepsis or septic shock. Anesthesiology, 92: 905-907. 